\title{
Distribution of Regulatory T-Cells and Other Phenotypes of T-Cells in Tumors and Regional Lymph Nodes of Colorectal Cancer Patients
}

\author{
KEISUKE KAZAMA ${ }^{1,2^{*}}$, JUNYA OTAKE ${ }^{3 *}$, TETSUTA SATOYOSHI ${ }^{1}$, MANABU SHIOZAWA ${ }^{1}$, NOBUHIRO \\ SUGANO $^{1}$, SUMITO SATO ${ }^{1}$, YOSUKE ATSUMI ${ }^{2}$, KAZUKI KANO $^{2}$, MASAAKI MURAKAWA $^{2}$, YUKIO \\ MAEZAWA $^{2}$, ITARU HASHIMOTO ${ }^{2}$, MASAKATSU NUMATA ${ }^{2}$, TAKASHI OSHIMA ${ }^{1}$, NORIO YUKAWA ${ }^{2}$, YASUSHI \\ RINO $^{2}$, TETSURO SASADA ${ }^{3}$ and MUNETAKA MASUDA ${ }^{2}$ \\ ${ }^{1}$ Department of Gastrointestinal Surgery, Kanagawa Cancer Center, Yokohama, Japan; \\ ${ }^{2}$ Department of Surgery, Yokohama City University, Yokohama, Japan; \\ ${ }^{3}$ Cancer Vaccine Center, Kanagawa Cancer Center, Yokohama, Japan
}

\begin{abstract}
Background/Aim: Tumor microenvironments consist of many types of immune cells, in which regulatory T-cells (Tregs) are supposed to play important roles to suppress antitumor immunity. Regional lymph nodes are essential for antitumor immunity in colorectal cancer (CRC). In this study, we compared the diversity of phenotypes of T-cells in normal tissue and regional lymph nodes in order to determine the immunosuppressive mechanism of lymph node metastasis of CRC. Patients and Methods: Fifty patients were enrolled in this study, and paired samples (tumor tissue, normal tissue, and three regional lymph node samples and as well as non-regional lymph node samples) were obtained from each patient. In each paired-sample set, the proportions of different immune cell types and T-cells expressing immune checkpoint molecules were compared using flow cytometry. Results: Higher proportions of Tregs $17.58 \%(4.94 \%-13.87 \%)$ vs. $1.79 \%(0.03 \%-5.36 \%)$, $p<0.001]$ and lower proportions of INF $\gamma$-producing CD4positive T (iCD4+) cells [21.49\% (12.08\%-27.35\%) vs. $26.55 \%$ (15.65\%-37.63\%), $p<0.001]$ were observed in tumor tissue than in normal mucosa. Parts of regional lymph nodes nearest the tumor had a greater proportion of Tregs [5.86\% $14.18 \%$ $7.69 \%)]$ and lower proportions of iCD4+ [5.94\% $(3.51 \%$ 9.04\%)] and INF $\gamma$-producing CD8-positive $T$ (iCD8+) cells
\end{abstract}

This article is freely accessible online.

*These Authors contributed equally to this study.

Correspondence to: Keisuke Kazama, Department of Gastrointestinal Surgery, Kanagawa Cancer Center, 3-9 Fukuura, Kanazawa-ku, Yokohama 236-0004, Japan. Tel: +81 0457872800, e-mail: c_falcon_kk@yahoo.co.jp

Key Words: Regulatory T-cells, colorectal cancer, lymph node, immune check point.
[21.93\% (14.92\%-35.90\%)] than distant parts of regional lymph nodes and non-regional lymph nodes. Both immunesuppressing molecules (CTLA-4 and PD-1) and immunepromoting molecules (OX-40 and ICOS) tended to be highly expressed in tumor tissue and local lymph nodes. Conclusion: In patients with CRC, regional lymph nodes, especially the parts nearest the tumor, had a higher proportion of Tregs and other suppressive immunophenotypes of T-cells than those located more distantly.

Colorectal cancer (CRC) is the third most common cancer worldwide, ranking as the second leading cause of cancerrelated death (1), and effective treatments are still urgently needed. As with many other carcinomas, metastasis to lymph nodes is a major method of progression and a strong prognostic factor of CRC. Clarifying the mechanisms underlying lymph node metastasis is, therefore, critically important and may lead to development of novel treatments.

In recent years, immunosuppressive cells and molecules have been found to be key issues that break down the established anticancer immune system in humans. Studies have shown that regulatory T-cells (Tregs), which are major contributors to sustaining self-tolerance and immune homeostasis by suppressing a wide variety of physiological and pathological immune responses $(2,3)$, play important roles in promoting the progression of many types of malignancies (4-14). A high frequency of Tregs among tumor-infiltrating lymphocytes (TILs) has been observed to be a poor prognostic factor in gastric cancer, lung cancer, endometrial carcinoma and breast cancer (15-19). In CRC, however, the function of Tregs remains uncertain, as the colon and rectum have different distributions of immune cells from other organs due to their bacteria-rich environments (20-23). In addition, there have been few reports on malignancy investigating the distribution of Tregs 
and other immune cells in regional lymph nodes, with none focusing on CRC in particular.

In the present study, we comprehensively investigated the phenotypes and functions of T-cells existing not only in tumors, but also the regional and non-regional lymph nodes (NRLNs) in order to determine the immunosuppressive mechanism of lymph node metastasis of CRC.

\section{Patients and Methods}

Patients and samples. We studied specimens of tumor tissues, paired adjacent normal mucosa ( $5 \mathrm{~cm}$ from the oral side of the tumor) and lymph nodes from the colon or rectum of 50 patients who had been diagnosed with CRC and undergone surgery of the primary site as the first treatment at the Department of Gastrointestinal Surgery of Kanagawa Cancer Center between May 2016 and 2018 March. Patients with the following were excluded: 1) synchronous or metachronous malignancies in other organs (within the past five years), 2) current usage of steroids or other immunosuppressants, and 3) current treatment for infectious diseases. Informed consent was obtained and documented from each participant, and the Ethics Committees of Kanagawa Cancer Center (approval number: 28study-22) approved the study before its initiation.

Tumor tissue, normal mucosa and lymph nodes were collected in normal saline as soon as the surgical specimens had been removed from the patients. Regional lymph nodes were collected from all three lymph node dissection levels: peri-intestinal lymph node (PLN), intermediate lymph node (ILN) and main lymph node (MLN). In addition, PLNs located more than $10 \mathrm{~cm}$ from the tumor were also collected as NRLN. Each lymph node was halved and sent for a pathological diagnosis. Soon after obtaining each sample, we shattered them to cellular samples as follows: lymph nodes were crushed, filtered and washed in phosphate-buffered saline (PBS) and centrifuged; the tumor and normal mucosa were pared down to $<5-\mathrm{mm}$ pieces and subjected to collagenase, processed with the Gentle MACSTM (WAKENYAKU CO., LTD, Kyoto, Japan) and then centrifuged.

Flow cytometry. Flow cytometry was performed to measure the Tregs, INF- $\gamma$-producing CD4-positive $\mathrm{T}$ (iCD4+) and CD8-positive $\mathrm{T}$ (iCD8+) cells (Figure 1), and immune checkpoint molecules. To count Tregs, cell staining was performed with the True-Nuclear One Step Staining Human Treg Flow Kit (BioLegend Way, San Diego, CA, USA). Surface staining was performed with the following fluorophoreconjugated anti-human monoclonal antibodies: anti-CD4-FITC or PEcy7, anti-CD8-BV421 or -APCcy7, anti-PD1-PEcy7, anti-CTLA4APC, anti-CD278-FITC, and anti-CD134-APC (BD Bioscience, San Jose, CA, USA). After incubation with each antibody dilution, samples were centrifuged and suspended in PBS. For the measurement of intracellular IFN $\gamma$, samples were treated with PMA and A23187 for the purpose of lymphocyte stimulation for $12 \mathrm{~h}$ in the presence of brefeldin-A (Sigma-Aldrich, St. Louis, MO, USA). The stimulated cells were attained with anti-CD4-FITC and anti-CD8-APCcy7, and then treated with Cytofix/Cytoperm. The fixed cells were stained with anti-IFN $\gamma$-PEcy7 (BD Bioscience, San Jose, CA, USA).

The stained samples were stirred and then analyzed using a BD FACS CantoII flow cytometer (BD Bioscience, San Jose, CA, USA) (Figure 1). Alive lymphocytes were initially gated based on the forward- and side-scatter features. The lymphocyte region was then used to obtain the gated fluorescence plot in all samples. In the present study, CD4-, CD25- and FOXP3-positive T-cells were considered conventional Tregs.

Statistical analyses. The proportion of Tregs, iCD4+ cells among all CD4-positive T-cells and iCD8+ among all CD8-positive T-cells were examined. Paired samples from tumor tissue and normal mucosa as well as PLN, ILN, MLN and NRLN were compared by Wilcoxon's matched-pairs signed-rank test. Unpaired comparisons of populations of each immune cell stratified by clinicopathological factors were evaluated by the Mann-Whitney $U$-test. All of the statistical analyses were performed with EZR, which is a graphical user interface for $\mathrm{R}$ (The R Foundation for Statistical Computing, Vienna, Austria; version 2.13.0). More precisely, it is a modified version of $\mathrm{R}$ commander designed to add statistical functions frequently used in biostatistics. Two-sided $p$-values were calculated, and differences were considered to be statistically significant at $p<0.05$.

\section{Results}

Patient enrollment and sample collections. Fifty patients were enrolled, and their clinicopathological background characteristics are shown in Table I. T3/4 was noted in 78\%, and $58 \%$ of all patients had regional LN metastasis. Distant metastasis was found in $22 \%$. Left-sided cancer was detected in the majority of cases in the present study.

From all enrolled patients, we obtained 49 sample sets of tumor tissue and normal mucosa. We missed 5 samples of ILNs, 10 of MLNs and 18 of NDLNs because lymph node dissection of the applicable region was not performed or no lymph node samples were found in the resected region. For NRLNs in particular, which were additionally dissected for the purpose of securing blood flow for anastomosis, the amount of specimen was often too small to evaluate. We also excluded data from hypocellular samples or those with a poorly stained lymphocyte condition.

Differences in T cell subpopulations between tumor tissue and normal mucosa. In paired samples of tumor and normal mucosa, the proportion of Tregs was significantly higher in tumor tissue than in normal mucosa $[7.58 \%(4.94 \%-13.87 \%)$ vs. $1.79 \%(0.03 \%-5.36 \%), p<0.001]$. In contrast, tumor tissue had lower proportions of iCD4+ cells than normal mucosa [21.49\% (12.08\%-27.35\%) vs. 26.55\% (15.65\%$37.63 \%), p<0.001]$. We found no significant differences in the iCD8+ cell proportions between the tissue types $[52.70 \%$ (36.86\%-65.37\%) vs. $46.73 \%$ (32.00\%-68.10\%), $p=0.583]$. Matched-pairs tests were performed for 30 pairs for Tregs, 44 pairs for iCD4+ cells, and 45 pairs for iCD8+ cells.

Differences in T cell subpopulations between lymph nodes. The proportion of Tregs in PLNs [5.86\% (4.18\%-7.69\%)] was significantly higher than in ILNs [4.49\% $(3.48 \%$ $6.02 \%), p<0.001]$ and MLNs [3.40\% $(2.19 \%-5.15 \%)$, $p<0.001]$. Similarly, ILNs had higher proportions of Tregs than MLNs $(p=0.002)$. In addition, there was a significant 
A

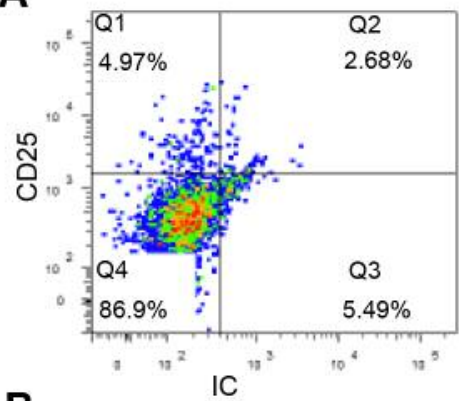

B

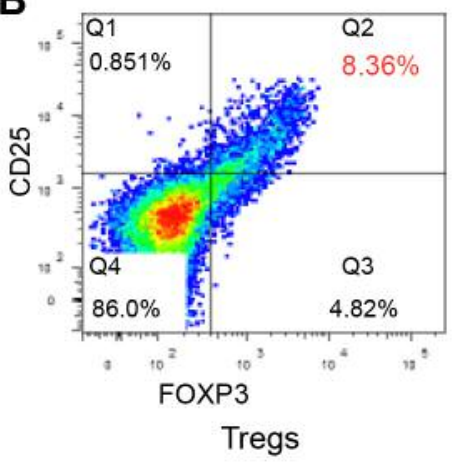

C
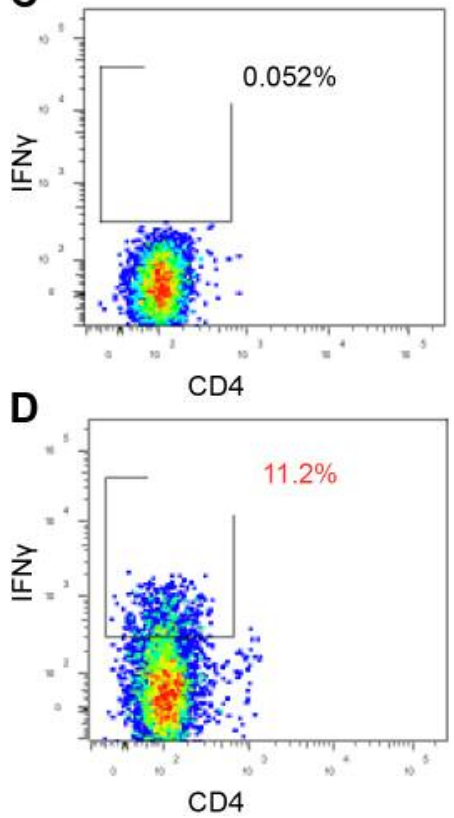

IFNy-positive CD4 T-cells
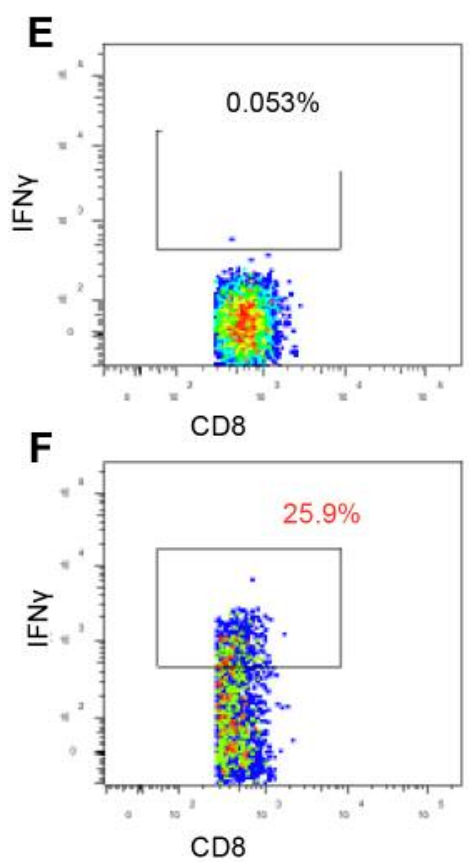

IFNy-positive CD8 T-cells

Figure 1. Counting of Tregs, IFN $\gamma$-positive CD4/CD8 T-cells by flow cytometry. (A) and (B) are representative flow cytometry color density plots depicting CD25 and isotype control (IC) (A), and FOXP3 (B) within a CD4+ T-cell gate. $(C)$ and $(D)$ are depicting CD4 and INF $\gamma$ before $(C)$ and after $(D)$ stimulation within a CD4/CD8 lymphocyte gate. $(E)$ and $(F)$ are depicting CD8 and INF $\gamma$ before $(E)$ and after $(F)$ stimulation.

difference in the Treg proportion between PLNs and NRLNs [3.74\% (2.72\%-5.93\%), $p=0.003$ ] (Figure 2).

Figure 3 shows the frequency of iCD8+ cells in each lymph node type. In contrast to the distribution of Tregs, iCD8+ cells were less frequent in PLNs $[21.93 \%$ (14.92\%$35.90 \%)$ ] than in ILNs [32.60\% (23.23\%-45.64\%), $p<0.001]$, MLNs [32.58\% (16.22\%-50.01\%), $p=0.039]$ and NRLNs [33.85\% (21.13\%-49.32\%), $p=0.015]$.

The proportion of iCD4+ cells was 5.94\% (3.51\%-9.04\%) in PLNs, $8.18 \%$ (5.34\%-13.76\%) in ILNs, $8.08 \%$ (3.93\%$11.10 \%)$ in MLNs, and $8.40 \%(5.10 \%-12.45 \%)$ in NRLNs (Figure 4). Similar to the observation with iCD8+ cells, significant differences were confirmed between PLNs and ILNs $(p<0.001)$ and NRLNs $(p=0.046)$.

Immunocheckpoints status of T-cells in tumor tissue and normal mucosa. Regarding immunosuppressive molecules, the proportion of T-cells expressing CTLA-4 was significantly higher in tumor tissue (CD4+: $p<0.001, \mathrm{CD} 8+$ : $p=0.017$ ), and the proportion of CD8+Tcells expressing Programmed cell death 1 (PD-1) status tended to be higher $(p=0.070)$ than in normal mucosa.

Regarding molecules promoting an immune response, the proportion of CD4+ and CD8+ cells expressing CD134 (OX40) were higher in tumor tissue than in normal mucosa
Table I. Patient characteristics.

\begin{tabular}{lc}
\hline Factor & $\mathrm{N}=50(\%$ or range $)$ \\
\hline Age, median (years) & $66(33-84)$ \\
Gender & $25(50) / 25(50)$ \\
Male/Female & $12(24) / 38(76)$ \\
Location \\
Right/Left \\
T-factor \\
1/2/3/4 & $4(8) / 7(14) / 21(42) / 18(36)$ \\
N-factor & $21(42) / 13(26) / 16(32)$ \\
$0 / 1 / 2$ & $39(78) / 11(22)$ \\
M-factor & \\
$0 / 1$ & $7(14) / 13(26) / 19(38) / 11(22)$ \\
pStage & $40(10-98)$ \\
I/II/III/IV & \\
Tumor diameter, median $(\mathrm{mm})$ &
\end{tabular}

(CD4+: $p=0.003, \mathrm{CD} 8+: p=0.001)$. The same findings applied to the expression of CD278 (ICOS) (CD4+: $p=0.001, \mathrm{CD} 8+: p<0.001)$.

Immunocheckpoint status of T-cells in lymph nodes. T cell populations expressing CTLA-4 were larger in PLNs than in 

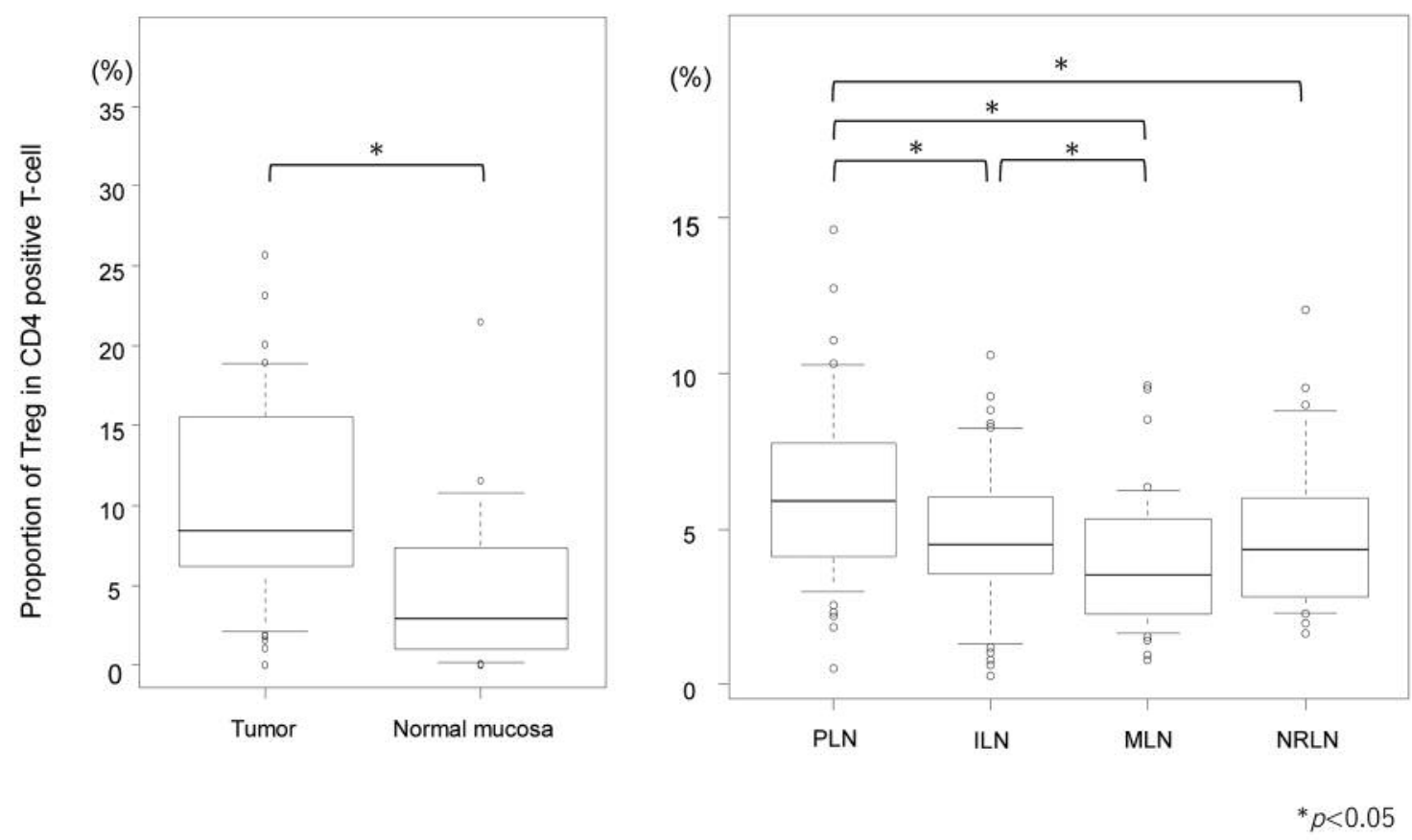

Figure 2. Proportion of Tregs in tumor, normal mucosa, and lymph nodes. Mean proportion of Tregs by tissue compartment in patients with CRC with comparison of means by Wilcoxon matched-pairs signed-rank test. There was a significantly higher proportion of Tregs in tumor than normal mucosa, and a clear order of proportion in lymph nodes according to its location.

ILNs (CD4+: $p=0.009, \mathrm{CD} 8+: p=0.052)$ or MLNs $(\mathrm{CD} 4+$ $p<0.001, \mathrm{CD} 8+: p=0.006)$ and tended to be larger than in NRLNs (CD4+: $p=0.182, \mathrm{CD} 8+: p=0.102)$. The tendency toward a larger population of T-cells with PD-1 expression in PLNs than in ILNs $(p=0.171)$ and MLNs $(p=0.002)$ was only seen in CD4+ cells.

Regarding the proportion of T-cells expressing molecules promoting an immune response, the proportion of CD4+ICOS+ cells was larger in PLNs than in ILNs $(p=0.014)$ or MLNs $(p=0.001)$ and tended to be larger in NRLNs $(p=0.162)$. The proportion of CD8+ICOS+ cells was larger in PLNs $(p=0.003)$ and ILNs $(p=0.074)$ than in MLNs. The proportion of CD8+OX40+ cells tended to be larger in PLNs $(p=0.110)$ and ILNs $(p=0.014)$ than in MLNs. CD4+OX40+ cells clearly showed a hierarchical relationship among lymph node regions, with the highest proportion noted in PLNs, followed by ILNs, MLNs and NRLNs.

\section{Discussion}

The present study clarified the existence of an anti-tumor immune microenvironment response in tumor tissues and lymph nodes in CRC. Our main finding was that a healthy proportion of Tregs is present in tumor tissue and neighboring lymph nodes compared to normal tissue and more remote lymph nodes. In contrast, T-cells capable of producing IFN $\gamma$, which is known to be a powerful mediator of inflammation, were present in almost inverse proportions to Tregs, with higher proportions being noted in the tumor tissue and PLNs than at other sites. Our results suggest that tumor progression to lymphoid tissue was affected by the immunosuppressive systems mainly produced by Tregs and that rescission of this mechanism may lead to novel treatments for CRC.

High numbers of Tregs in the TILs or peripheral blood have been reported among many types of malignancies (24-29), and in many cases, richness of Tregs was associated with a poor cancer prognosis (29-31). For example, Nabeki, et al. reported that esophageal cancer patients with a high proportion of Tregs in TILs had poorer prognosis than those with low proportion of Tregs (30). Moreover, in their study of the distribution of Th17 cells and Tregs in gastric cancer patients using flow cytometry, Maruyama, et al. found that the proportion of Th17/Tregs among TILs was markedly increased in the early stage of disease compared to the advanced stage (32). In addition, a decreased ratio of CD8+ cells to Tregs was verified to be associated with a poor prognosis in breast cancer patients by Bates et al. (33). Researchers have further demonstrated that Tregs actively suppress the tumor-specific immune responses in CRC patients (34-36), which is in line with the findings of the current investigation.

In CRC, however, contrary to these previous results, several studies have reported a high Treg proportion in TILs 

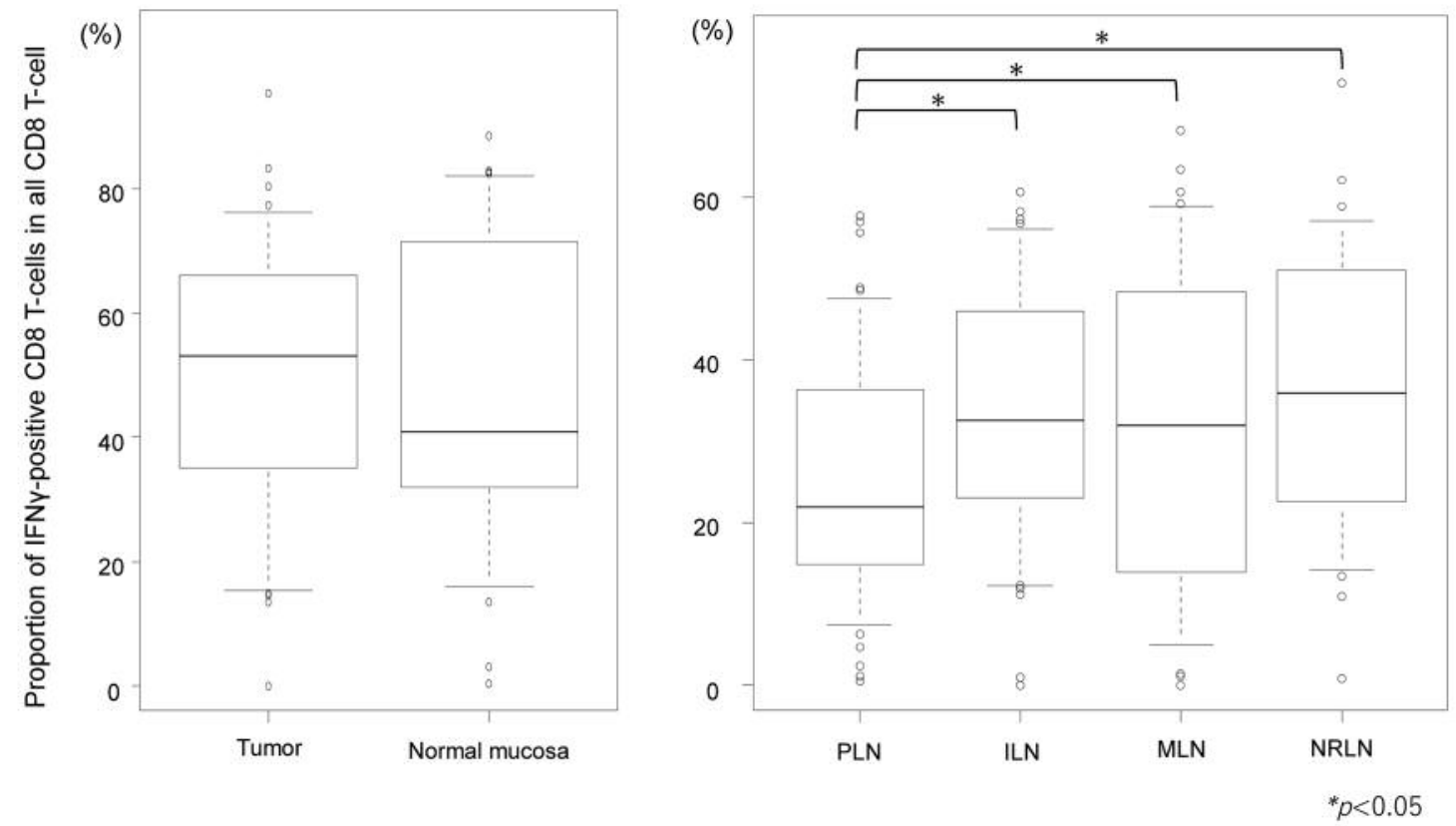

Figure 3. Proportion of IFN $\gamma$-positive CD8 T-cells in tumor, normal mucosa, and lymph node. Mean proportion of IFN $\gamma$-positive CD8 T-cells (iCD8) by tissue compartment. Hierarchy-like difference of proportion of $i C D 8$ were seen according to the lymph node location.

to be associated with better outcomes as evaluated by immunohistochemistry (37-39). This has prompted the hypothesis that, in CRC, the suppression of chronic inflammation by Tregs may prevail over the control of antitumor immunity $(38,40)$. Saito et al. recently showed that Tregs were classifiable into three subpopulations based on the expression of Foxp3 and the presence of CD45RA; they further found that Foxp3lowCD45RA- Tregs had the capacity to promote the antitumor immune system (41). In the present study, we tried but were unable to classify Tregs into subpopulations clearly using Foxp3 and CD45RA.

To the best of our knowledge, this is the first report that comprehensively investigated the immune cell subsets existing not only in tumor tissue but also normal tissue as well as lymph nodes around the carcinoma, containing both drainage and non-drainage lymph nodes. Our results revealed an increased proportion of Tregs in drainage lymph nodes adjacent to the tumor compared with more remote ones. In contrast, iCD4+ and iCD8+ cell proportions were decreased in PLNs compared with lymph nodes located in more distant regions. The same result was also seen in the comparison of PLNs and NRLNs. In a handful of series from previous studies, researchers investigated the subset of immune cells of lymph nodes located around carcinoma of other organs. With gastric cancer patients, Mizukami et al. found an increased proportion of Tregs in the drainage lymph nodes compared with the non-drainage ones (42). There have been several reports on the drainage lymph nodes of non-small cell lung cancer (NSCLC) $(43,44)$. Murthy et al. investigated the differences in the distributions of immune cells between drainage and non-drainage lymph nodes using samples from 20 NSCLC patients by flow cytometry. In their study, drainage lymph nodes showed a suppressive immunophenotype, having a lower proportion of effector CD4+ cells and a higher proportion of Tregs than the paired NRLNs (45). These findings suggest that because of the energy mediated by Tregs, the immune system against progression of carcinoma was attenuated, and such immunosuppressive microenvironment spread to lymph nodes around the tumor. The proportion of Tregs and iCD4/CD8 cells was almost equal between MLNs and NRLNs in our investigation. Many clinical studies have demonstrated the diluted significance of preventative dissection of MLNs, and our results may support this idea from an immunological perspective, as NRLNs are considered outside of the resection range in Japanese guidelines.

Co-signaling molecules play a critical role in regulating the immune response. Based on their function, co-signaling molecules are classified into two groups: co-stimulatory and coinhibitory molecules. For the co-inhibitory receptors, the proportion of CD4+/CD8+ cells expressing CTLA-4 or PD-1 is generally higher among TILs and T-cells in adjacent lymph nodes than in normal tissue and remote lymph nodes. Surprisingly, we also found a high proportion of CD4+/CD8+ cells expressing ICOS and OX40 in tumor tissue and adjacent lymph nodes in the present study. Given our observations of reduced proportions of $\mathrm{iCD} 4+$ and $\mathrm{iCD} 8+$ cells in tumor tissue 

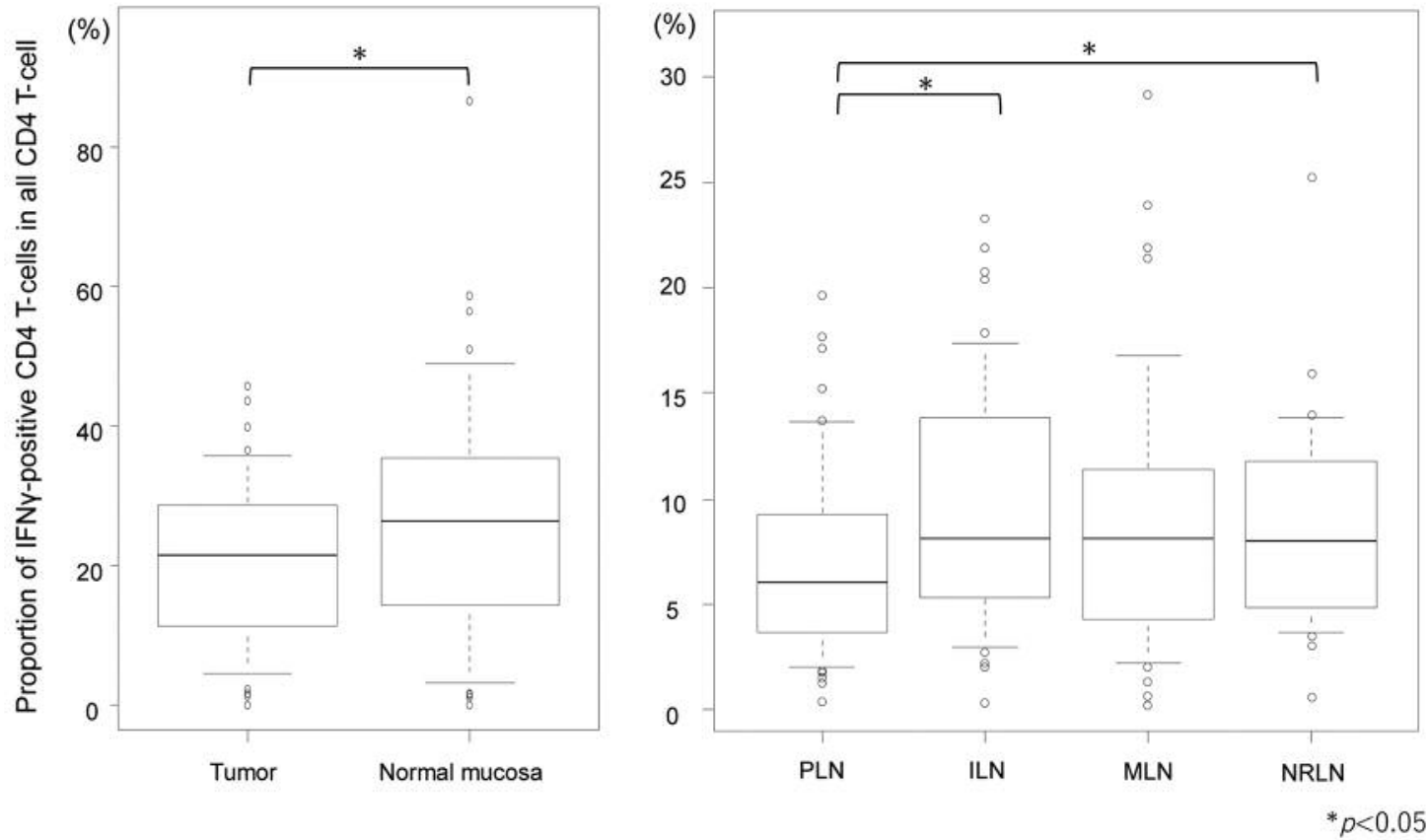

Figure 4. Proportion of IFN $\gamma$-positive CD4 T-cells in tumor, normal mucosa, and lymph node. Mean proportion of IFN $\gamma$-positive CD4 T-cells (iCD4) by tissue compartment. The proportion was higher in tumor than normal mucosa, and in PLNs than ILN and NRLN.

and adjacent lymph nodes, the microenvironment of the tumor was likely created by the competition of anti-tumor reactions and tolerance effects, following the three phases theory advocated by Shitara and Nishikawa (46). The immunosuppressive mechanisms induced by the interaction between dendric cells and Tregs by the CTLA-4 are well-known (47). The effects of PD-1 inhibition by Tregs remain to be determined, but PD-1 has been reported to be highly expressed on Tregs and may be involved in immunosuppressive mechanisms related to Tregs (48-50). Verifying and comparing the repertoire of $\mathrm{T}$ cell receptor among regions may prove the idea of the prevalence of an immunosuppressive microenvironment and lead to a further understanding of the mechanisms involved in cancer progression.

In conclusion, as is the case with tumor tissue, regional lymph nodes-especially those near the tumor-showed a higher proportion of Tregs with suppressive immunophenotypes of Tcells than normal mucosa and more distant lymph nodes.

\section{Conflicts of Interest}

The Authors have no conflicts of interest to declare with regard to this study.

\section{Authors' Contributions}

Keisuke Kazama, Junya Otake and Tetsuro Sasada made substantial contributions to the study conception and design. All of the Authors made substantial contributions to the collection, analysis and interpretation of data. The first draft of the manuscript was written by Keisuke Kazama and all Authors have been involved in revising it critically for important intellectual content. All Authors read and approved the final manuscript.

\section{Acknowledgements}

This work was supported, in part, by the Kanagawa Cancer Center Hospital-Research Institute Joint Study.

\section{References}

1 Ferlay J, Soerjomataram I, Dikshit R, Eser S, Mathers C, Rebelo M, Parkin DM, Forman D and Bray F: Cancer incidence and mortality worldwide: sources, methods and major patterns in GLOBOCAN 2012. Int J Cancer 136(5): 359-386, 2015. PMID: 25220842. DOI: $10.1002 / \mathrm{ijc} .29210$

2 Yoshida N, Kinugasa T, Miyoshi H, Sato K, Yuge K, Ohchi T, Fujino S, Shiraiwa S, Katagiri M, Akagi Y and Oshima K: A high ROR $\gamma \mathrm{T} / \mathrm{CD} 3$ ratio is a strong prognostic factor for postoperative survival in advanced colorectal cancer: analysis of helper T cell lymphocytes (Th1, Th2, Th17 and regulatory Tcells). Ann Surg Oncol 23(3): 919-927, 2016. PMID: 26564244. DOI: $10.1245 / \mathrm{s} 10434-015-4923-3$

3 Kimura A and Kishimoto T: IL-6: regulator of Treg/Th17 balance. Eur J Immunol 40(7): 1830-1835, 2010. PMID: 20583029. DOI: 10.1002/eji.201040391

4 Shimizu J, Yamazaki S and Sakaguchi S: Induction of tumor immunity by removing CD25+ CD4+ T-cells: a common basis 
between tumor immunity and autoimmunity. J Immunol 163(10): 5211-5218, 1999. PMID: 10553041.

5 Woo EY, Yeh H, Chu CS, Schlienger K, Carroll RG, Riley JL, Kaiser LR and June CH: Cutting edge: Regulatory T-cells from lung cancer patients directly inhibit autologous $\mathrm{T}$ cell proliferation. J Immunol 168(9): 4272-4276, 2002. PMID: 11970966. DOI: 10.4049/jimmunol.168.9.4272

6 Sutmuller RP, van Duivenvoorde LM, van Elsas A, Schumacher TN, Wildenberg ME, Allison JP, Toes RE, Offringa R and Melief CJ: Synergism of cytotoxic T lymphocyte-associated antigen 4 blockade and depletion of $\mathrm{CD} 25(+)$ regulatory T-cells in antitumor therapy reveals alternative pathways for suppression of autoreactive cytotoxic T lymphocyte responses. J Exp Med 194(6): 823-832, 2001. PMID: 11560997. DOI: 10.1084/jem.194.6.823

7 Cao M, Cabrera R, Xu Y, Firpi R, Zhu H, Liu C and Nelson DR: Hepatocellular carcinoma cell supernatants increase expansion and function of $\mathrm{CD} 4(+) \mathrm{CD} 25(+)$ regulatory T-cells. Lab Invest $87(6)$ : 582-590, 2007. PMID: 17372588. DOI: 10.1038/labinvest.3700540

8 Petersen RP, Campa MJ, Sperlazza J, Conlon D, Joshi MB, Harpole DH Jr and Patz EF Jr: Tumor-infiltrating foxp3+ regulatory T-cells are associated with recurrence in pathologic stage I NSCLC patients. Cancer 107(12): 2866-2872, 2006. PMID: 17099880 . DOI: $10.1002 / \mathrm{cncr} .22282$

9 Hinz S, Pagerols-Raluy L, Oberg HH, Ammerpohl O, Grüssel S, Sipos B, Grützmann R, Pilarsky C, Ungefroren H, Saeger HD, Klöppel G, Kabelitz D and Kalthoff H: Foxp3 expression in pancreatic carcinoma cells as a novel mechanism of immune evasion in cancer. Cancer Res 67(17): 8344-8350, 2007. PMID: 17804750. DOI: 10.1158/0008-5472.CAN-06-3304

10 Liu VC, Wong LY, Jang T, Shah AH, Park I, Yang X, Zhang Q, Lonning S, Teicher BA and Lee C: Tumor evasion of the immune system by converting CD4+ CD25- T-cells into CD4+ $\mathrm{CD} 25+\mathrm{T}$ regulatory cells: role of tumor-derived TGF-b. J Immunol 178(5): 2883-2892, 2007. PMID: 17312132. DOI: 10.4049/jimmunol.178.5.2883

11 Siddiqui SA, Frigola X, Bonne-Annee S, Mercader M, Kuntz SM, Krambeck AE, Sengupta S, Dong H, Cheville JC, Lohse CM, Krco CJ, Webster WS, Leibovich BC, Blute ML, Knutson KL and Kwon ED: Tumor-infiltrating Foxp3-CD4+CD25+ T-cells predict poor survival in renal cell carcinoma. Clin Can Res 13(7): 2075-2081, 2007. PMID: 17404089. DOI: 10.1158/1078-0432.CCR-06-2139

12 Vignali DA, Collison LW and Workman CJ: How regulatory Tcells work. Nat Rev Immunol 8(7): 523-532, 2008. PMID: 18566595. DOI: $10.1038 /$ nri2343

13 Ikemoto T, Shimada M, Ishikawa D, Kawashita Y, Teraoku H, Yoshikawa M, Yamada S, Saito Y, Morine Y and Imura S: Peripheral Tr1 and Foxp3+ Treg as markers of recurrent malignancies in patients with hepato-biliary pancreatic cancers. Anticancer Res 37(10): 5541-5552, 2017. PMID: 28982868. DOI: 10.21873 /anticanres.11986

14 Szylberg $€$, Karbownik D and Marszałek A: The role of FOXP3 in human cancers. Anticancer Res 36(8): 3789-3794, 2016. PMID: 27466478.

15 Meng X, Zhu S, Dong Q, Zhang S, Ma J and Zhou C: Expression of $\mathrm{Th} / 17 /$ Treg related molecules in gastric cancer tissues. Turk J Gastroenterol 29(1): 45-51, 2018. PMID: 29391307. DOI: $10.5152 /$ tjg.2018.17114

16 Miossec P and Kolls JK: Targeting IL-17 and TH17 cells in chronic inflammation. Nat Rev Drug Discov 11(10): 763-776, 2012. PMID: 23023676. DOI: $10.1038 /$ nrd3794
17 Chang SH, Mirabolfathinejad SG, Katta H, Cumpian AM, Gong L, Caetano MS, Moghaddam SJ and Dong C: T helper 17 cells play a critical pathogenic role in lung cancer. Proc Natl Acad Sci USA 111(15): 5664-5669, 2014. PMID: 24706787. DOI: $10.1073 /$ pnas. 1319051111

18 Zhang W, Hou F, Zhang Y, Tian Y, Jiao J, Ma D, Kong B and Cui B: Changes of Th17/Tc17 and Th17/Treg cells in endometrial carcinoma. Gynecol Oncol 132(3): 599-605, 2014. PMID: 24388919. DOI: 10.1016/j.ygyno.2013.12.036

19 Li Q, Li Q, Chen J, Liu Y, Zhao X, Tan B, Ai J, Zhang Z, Song $\mathrm{J}$ and Shan B: Prevalence of Th17 and Treg cells in gastric cancer patients and its correlation with clinical parameters. Oncol Rep 30(3): 1215-1222, 2013. PMID: 23807713. DOI: 10.3892/or.2013.2570

$20 \mathrm{Ma}$ C and Dong X: Colorectal cancer-derived Foxp3(+) IL-17(+) T-cells suppress tumor-specific CD8 + T-cells. Scand J Immunol 74(1): 47-51, 2011. PMID: 21352252. DOI: 10.1111/j.13653083.2011.02539.x

21 Yang S, Wang B, Guan C, Wu B, Cai C, Wang M Zhang B, Liu $\mathrm{T}$ and Yang P: Foxp3+IL-17+ T-cells promote development of cancer-initiating cells in colorectal cancer. J Leuk Biol 89(1): 85-91, 2011. PMID: 20952660. DOI: 10.1189/jlb.0910506

22 Mahalingam J, Lin CY, Chiang JM, Su PJ, Chu YY, Lai HY, Fang JH, Huang CT and Lin YC: CD4(+) T-cells expressing latency-associated peptide and Foxp3 are an activated subgroup of regulatory T-cells enriched in patients with colorectal cancer. PLoS One 9(9): e108554, 2014. PMID: 25268580. DOI: 10.1371/journal.pone.0108554

23 Tougeron D, Maby P, Elie N, Fauquembergue E, Le Pessot F, Cornic M, Sabourin JC, Michel P, Frébourg T and Latouche JB: Regulatory $\mathrm{T}$ lymphocytes are associated with less aggressive histologic features in microsatellite-unstable colorectal cancers. PLoS One 8(4): e61001, 2013. PMID: 23613769. DOI: 10.1371/journal.pone.0061001

24 Liyanage UK, Moore TT, Joo HG, Tanaka Y, Herrmann V, Doherty G, Drebin JA, Strasberg SM, Eberlein TJ, Goedegebuure PS and Linehan DC: Prevalence of regulatory T-cells is increased in peripheral blood and tumor microenvironment of patients with pancreas or breast adenocarcinoma. J Immunol 169(5): 27562761, 2002. PMID: 12193750. DOI:10.4049/jimmunol.169.5.2756

25 Wolf AM, Wolf D, Steurer M, Gastl G, Gunsilius E and Grubeck-Loebenstein B: Increase of regulatory T-cells in the peripheral blood of cancer patients. Clin Cancer Res 9(2): 606612, 2003. PMID: 12576425.

26 Hiraoka N, Onozato K, Kosuge T and Hirohashi S: Prevalence of FOXP3+ regulatory T-cells increases during the progression of pancreatic ductal adenocarcinoma and its premalignant lesions. Clin Cancer Res 12(18): 5423-5434, 2006. PMID: 17000676. DOI: 10.1158/1078-0432.CCR-06-0369

27 Curiel TJ, Coukos G, Zou L, Alvarez X, Cheng P, Mottram P, Evdemon-Hogan M, Conejo-Garcia JR, Zhang L, Burow M, Zhu Y, Wei S, Kryczek I, Daniel B, Gordon A, Myers L, Lackner A, Disis ML, Knutson KL, Chen L and Zou W: Specific recruitment of regulatory T-cells in ovarian carcinoma fosters immune privilege and predicts reduced survival. Nat Med 10(9): 942-949, 2004. PMID: 15322536 . DOI: 10.1038/nm1093

28 Ichihara F, Kono K Takahashi A, Kawaida H, Sugai H and Fujii H: Increased proportion of regulatory T-cells in peripheral blood and tumor-infiltrating lymphocytes in patient with gastric and esophageal cancers. Clin Cancer Res 9(12): 4404-4408, 2003. PMID: 14555512 
29 Wolf D, Wolf AM, Rumpold H, Fiegl H, Zeimet AG, MullerHolzner E, Deibl M, Gastl G, Gunsilius E and Marth C: The expression of regulatory T-cells-specific forkhead box transcription factor Foxp3 is associated with poor prognosis in ovarian cancer. Clin Cancer Res 11(23): 8326-8331, 2005. PMID: 16322292. DOI: 10.1158/1078-0432.CCR-05-1244

30 Nabeki B, Ishigami S, Uchikado Y, Sasaki K, Kita Y, Okumura $\mathrm{H}$, Arigami T, Kijima Y, Kurahara H, Maemura K and Natsugoe S: Interleukin-32 expression and Treg infiltration in esophageal squamous cell carcinoma. Anticancer Res 35(5): 2941-2947, 2015. PMID: 25964580.

31 Shang B, Liu Y, Jiang S and Liu Y: Prognostic value of tumorinfiltrating FoxP3+regulatory T-cells in cancers: a systematic review and meta-analysis. Sci Rep 5: 15179, 2015. PMID: 26462617. DOI: 10.1038/srep15179

32 Maruyama T, Kono K, Mizukami Y, Kawaguchi Y, Mimura K, Watanabe M, Izawa S and Fujii H: Distribution of Th17 cells and FoxP3(+) regulatory T-cells in tumor-infiltrating lymphocytes, tumor-draining lymph nodes and peripheral blood lymphocytes in patients with gastric cancer. Cancer Sci 101(9): 1947-1954, 2010. PMID: 20550524. DOI: 10.1111/j.1349-7006.2010.01624.x

33 Bates GJ, Fox SB, Han C, Leek RD, Garcia JF, Harris AL and Banham AH: Quantification of regulatory T-cells enables the identification of high-risk breast cancer patients and those at risk of late relapse. J Clin Oncol 24(34): 5373-5380, 2006. PMID: 17135638. DOI: $10.1200 / J C O .2006 .05 .9584$

34 Betts G, Jones E, Junaid S, El-Shanawany T, Scurr M, Mizen P, Kumar M, Jones S, Rees B, Williams G, Gallimore A and Godkin A: Suppression of tumour-specific CD4(+) T-cells by regulatory T-cells is associated with progression of human colorectal cancer. Gut 61(8): 1163-1171, 2012. PMID: 22207629. DOI: 10.1136/gutjnl-2011-300970

35 Bonertz A, Weitz J, Pietsch DH, Rahbari NN, Schlude C, Ge Y, Juenger S, Vlodavsky I, Khazaie K, Jaeger D, Reissfelder C, Antolovic D, Aigner M, Koch M and Beckhove P: Antigen-specific Tregs control $\mathrm{T}$ cell responses against a limited repertoire of tumor antigens in patients with colorectal carcinoma. J Clin Invest 119(11): 3311-3321, 2009. PMID: 19809157. DOI: 10.1172/JCI39608

36 Clarke SL, Betts GJ, Plant A, Wright KL, El-Shanawany TM, Harrop R, Torkington J, Rees BI, Williams GT, Gallimore AM and Godkin AJ: CD4+CD25+FOXP3+ regulatory T-cells suppress anti-tumor immune responses in patients with colorectal cancer. PLoS One 1: e129, 2006. PMID: 17205133. DOI: 10.1371 /journal.pone.0000129

37 deLeeuw RJ, Kost SE, Kakal JA and Nelson BH: The prognostic value of FoxP3Ctumor-infiltrating lymphocytes in cancer: a critical review of the literature. Clin Cancer Res 18(11): 30223029, 2012. PMID: 22510350. DOI: 10.1158/1078-0432.CCR11-3216

38 Ladoire S, Martin F and Ghiringhelli F: Prognostic role of FOXP3+ regulatory T-cells infiltrating human carcinomas: the paradox of colorectal cancer. Cancer Immunol Immunother 60(7): 909-918, 2011. PMID: 21644034. DOI: 10.1007/s00262011-1046-y

39 Salama P, Phillips M, Grieu F, Morris M, Zeps N, Joseph D, Platell $\mathrm{C}$ and Iacopetta B: Tumor-infiltrating FOXP3+ T regulatory cells show strong prognostic significance in colorectal cancer. J Clin Oncol 27(2): 186-192, 2009. PMID: 19064967. DOI: $10.1200 / J C O .2008 .18 .7229$
40 Gallimore AM and Simon AK: Positive and negative influences of regulatory T-cells on tumour immunity. Oncogene 27(45): 5886-5893, 2008. PMID: 18836469. DOI: 10.1038/onc.2008.269

41 Saito T, Nishikawa H, Wada H, Nagano Y, Sugiyama D, Atarashi K, Maeda Y, Hamaguchi M, Ohkura N, Sato E, Nagase H, Nishimura J, Yamamoto H, Takiguchi S, Tanoue T, Suda W, Morita H, Hattori M, Honda K, Mori M, Doki Y and Sakaguchi S: Two FOXP3+CD4+ T cell subpopulations distinctly control the prognosis of colorectal cancers. Nat med 22(6): 679-686, 2016. PMID: 27111280. DOI: $10.1038 / \mathrm{nm} .4086$

42 Mizukami Y, Kono K, Kawaguchi Y, Akaike H, Kamimura K, Sugai $\mathrm{H}$ and Fujii H: CCL17 and CCL22 chemokines with tumor microenvironment are related to accumulation of Foxp3+ regulatory T-cells in gastric cancer. Int J Cancer 122(10): 22862293, 2008. PMID: 18224687. DOI: 10.1002/ijc.23392

43 Hanagiri T, Shigematsu Y, Shinohara S, Takenaka M, Oka S, Chikashi Y, Nagata Y, Iwata T, Uramoto H, So T and Tanaka F: Clinical significance of the frequency of regulatory T-cells in regional lymph node lymphocytes as a prognostic factor for nonsmall-cell lung cancer. Lung Cancer 81(3): 475-479, 2013. PMID: 23891508. DOI: 10.1016/j.lungcan.2013.07.001

44 Zeng L, O'Connor C, Zhang J, Kaplan AM and Cohen DA: IL10 promotes resistance to apoptosis and metastatic potential in lung tumor cell lines. Cytokine 49(3): 294-302, 2010. PMID: 20034810. DOI: 10.1016/j.cyto.2009.11.015

45 Murthy V, Katzman DP, Tsay JJ, Bessich JL, Michaud GC, Rafeq S, Minehart J, Mangalick K, de Lafaille MAC, Goparaju C, Pass H and Sterman DH: Tumor-draining lymph nodes demonstrate a suppressive immunophenotype in patients with non-small cell lung cancer assessed by endobronchial ultrasound-guided transbronchial needle aspiration: A pilot study. Lung Cancer 137: 94-99, 2019. PMID: 31563736. DOI: 10.1016/j.lungcan.2019.08.008

46 Shitara K and Nishikawa H: Regulatory T-cells: a potential target in cancer immunotherapy. Ann NY Acad Sci 1417(1): 104115, 2018. PMID: 29566262. DOI: 10.1111/nyas.13625

47 Gabrilovich DI: Myeloid-derived suppressor cells. Cancer Immunol Res 5(1): 3-8, 2017. PMID: 28052991. DOI: 10.1158/2326-6066.CIR-16-0297

48 Kamada T, Togashi Y, Tay C, Ha D, Sasaki A, Nakamura Y, Sato E, Fukuoka S, Tada Y, Tanaka A, Morikawa H, Kawazoe A, Kinoshita T, Shitara K, Sakaguchi S and Nishikawa H: PD-1(+) regulatory T-cells amplified by $\mathrm{PD}-1$ blockade promote hyperprogression of cancer. Proc Natl Acad Sci USA 116(20): 999910008, 2019. PMID: 31028147. DOI: 10.1073/pnas.1822001116

49 Thommen DS and Schumacher TN: T cell dysfunction in cancer. Cancer Cell 33(4): 547-562, 2018. PMID: 29634943. DOI: 10.1016/j.ccell.2018.03.012

50 Zhang B, Chikuma S, Hori S, Fagarasan S and Honjo T: Nonoverlapping roles of PD-1 and FoxP3 in maintaining immune tolerance in a novel autoimmune pancreatitis mouse model. Proc Natl Acad Sci USA 113(30): 8490-8495, 2016. PMID: 27410049. DOI: 10.1073/pnas.1608873113

Received December 17, 2019

Revised January 10, 2020

Accepted January 13, 2020 